\title{
Wilson's Disease and Ulcerative Colitis in the Same Patient: Just A Coincidence? A Case Report and Literature Review
}

\author{
Filipe G. Nery ${ }^{\mathrm{a}, \mathrm{c}}$, Irene Marques ${ }^{\mathrm{a}}$, Marina Magalhaes ${ }^{\mathrm{b}}$, Helena P. Miranda ${ }^{\mathrm{a}}$
}

\begin{abstract}
Ulcerative Colitis (UC) is a chronic relapsing inflammatory bowel disease (IBD). Wilson's disease (WD) is a disorder of copper $(\mathrm{Cu})$ metabolism due to inherited mutations in a gene encoding a putative $\mathrm{Cu}$-transporting P-type ATPase, with a heterogeneous clinical presentation that includes hepatic, neurological, or psychiatric symptoms. The case of a 17-year-old female that presented with severe liver failure, three years after UC onset, and in which diagnosis of WD was established is reported. We review the literature and discuss the possible association between the two rare diseases. Although evidence of a common genetic background between UC and WD has not been described, high $\mathrm{Cu}$ serum level is present in both diseases. $\mathrm{Cu}$ is one of the trace elements necessary for antioxidant defenses during inflammatory processes, affecting the production of free radicals of oxygen and the levels of cellular antioxidants. The presence of both entities in the same patient may suggest abnormal metabolism of $\mathrm{Cu}$ or be just a coincidence.
\end{abstract}

Keywords: Wilson's disease; Ulcerative colitis; Association; Copper

\section{Introduction}

Wilson's disease (WD) is a rare genetically autosomal recessive inherited disorder of copper $(\mathrm{Cu})$ metabolism that affects mainly children, adolescents and young adults. The ATP7B gene mutations (in chromosome 13) $[1,2]$ result

Manuscript accepted for publication December 16, 2010

\footnotetext{
${ }^{a}$ Medicine Service, CHP - Hospital Sto Antonio, Porto, Portugal ${ }^{b}$ Neurology Service, CHP - Hospital Sto Antonio, Porto, Portugal ${ }^{\mathrm{c} C}$ Corresponding author: Centro Hospitalar do Porto, Servico de Medicina, Largo do Prof. Abel Salazar 4099-001 Porto, Portugal. Email: filipegaionery@gmail.com
}

doi:10.4021/gr271w in an inadequate excretion of absorbed dietary $\mathrm{Cu}$ via bile and in the accumulation of toxic amounts of $\mathrm{Cu}$ in liver and other organs [3, 4]. The diagnosis of WD is based on clinical and laboratory findings, including low serum ceruloplasmin $(\mathrm{CP})$, increased urinary $\mathrm{Cu}$ excretion and hepatic $\mathrm{Cu}$ content [5]. In recent years, the development of new techniques in genetic and molecular biology has provided useful tools in the diagnosis of WD [6]. Ulcerative colitis (UC) is a rare inflammatory bowel disease that affects colorectal mucosa. Genetic susceptibility has been described, namely HLA antigens class II [8], and genomic linkage to chromosomes 3, 5, 7 and 12 [7]. The diagnosis takes into account clinical, endoscopic and radiologic findings, as well as histological features.

The clinical association between UC and autoimmune liver diseases, such as primary sclerosing cholangitis [8-10] and hepatitis [11] is well known, though the association with WD is very uncommon.

\section{Case Report}

A 17-year-old female was diagnosed with UC, based on characteristic clinical and endoscopic findings: bloody diarrhea, hyperemia and friability of the colonic mucosa with scattered erosions up to $20 \mathrm{~cm}$ from the anal margin, supported by histological features.

She was treated with mesalazine and corticosteroid during relapses. Three years after UC onset, she was admitted to another hospital with a two-month history of nausea, vomiting, jaundice and abdominal pain. Fever, clinical signs of encephalopathy or ascitis were not present. Laboratory data at admission showed increased aspartate transferase (AST $=$ $113 \mathrm{IU} / \mathrm{L} ; \mathrm{N}<32$ ), gamma-glutamyl transferase (GGT $=223$ $\mathrm{IU} / \mathrm{L}, \mathrm{N}<39)$ and total bilirubin $(\mathrm{TB}=21.94 \mathrm{mg} / \mathrm{dL}$, conjugated bilirubin of $11.19 \mathrm{mg} / \mathrm{dL}$ ). Alanine aminotransferase was slightly increased $(\mathrm{ALT}=32 \mathrm{IU} / \mathrm{L} ; \mathrm{N}<28)$ and alkaline phosphatase (AP $=21 \mathrm{IU} / \mathrm{L} ; \mathrm{N}<104)$ was within normal range. Serum albumin was decreased $(\mathrm{Alb}=2.4 \mathrm{~g} / \mathrm{dL} ; 3.5$ $<\mathrm{N}<5.0$ ), prothrombin time prolonged at 6.7 seconds and the platelet count was normal. Hemoglobin was $9.6 \mathrm{~g} / \mathrm{dL}$, and she was Coombs negative. She presented a leukocytosis 
$\left(\mathrm{WBC}=13.1 \times 10^{3} / \mu \mathrm{L} ; 4.1<\mathrm{N}<10.9 \times 10^{3} / \mu \mathrm{L}\right)$ with neutrophilia $\left(8.69 \times 10^{3} / \mu \mathrm{L}\right)$. Serologies for hepatitis A, B and $\mathrm{C}$ were negative as well as for HIV1 and 2, EBV, CMV and toxoplasma. Anti-nuclear antibodies, anti-LKM, LC1, SLA/ LP, smooth muscle and anti-mitochondria were all negative. Only atypical PANCA (X-ANXA) was positive in a titer of 1/80. Alpha1-antitrypsin $(241 \mathrm{mg} / \mathrm{dL} ; 90<\mathrm{N}<169 \mathrm{mg} /$ $\mathrm{dL})$ and $\mathrm{C}$ reactive protein $(1.28 \mathrm{mg} / \mathrm{dL} ; \mathrm{N}<0,50 \mathrm{mg} / \mathrm{dL})$ were elevated. Due to the clinical suspicion of cholangitis, antibiotherapy with piperacillin and tazobactam was started. Two days later, her health condition deteriorated and she was referred to our hospital. Total bilirubin increased up to 57.4 $\mathrm{mg} / \mathrm{dL}$ and prothrombin time was prolonged over $16 \mathrm{sec}$. An upper abdominal ultrasound examination showed a discrete hepatomegaly $(16 \mathrm{~cm})$, with normal echostructure and a normal biliary tree. A transjugular liver biopsy revealed portal and perisinusoidal bridging fibrosis, with moderate inflammatory activity, compatible with cirrhosis. The colonoscopy was not repeated.

The diagnosis of WD was established, based on the presence of Kayser-Fleischer rings in the slit-lamp examination, a low serum ceruloplasmin $(\mathrm{CP}=0.11 \mathrm{~g} / \mathrm{L} ; 0.18<\mathrm{N}<$ $0.53)$, elevated $24-\mathrm{h}$ urine $\mathrm{Cu}(24 \mathrm{hU} \mathrm{Cu}=128.128 \mu \mathrm{mol} / \mathrm{d}$; $0.040<\mathrm{N}<0.550)$, and elevated hepatic tissue $\mathrm{Cu}(\mathrm{TCu}=$ $1112.51 \mu \mathrm{g} / \mathrm{g}$ dry weight; $10.00<\mathrm{N}<35.00)$. Neurological examination and cerebral MRI were normal. Genetic testing confirmed the diagnosis Allele1: c.3207C $>$ A(p.His1069Gin) and Allele 2: c.3061-12T(IVS14-12T $>$ A. She was initially treated with trientine $(250 \mathrm{mg} /$ day $)$ and zinc acetate $(50 \mathrm{mg}$ bid), resulting in progressive clinical and liver function improvement, and was discharged home two weeks after the initiation of treatment. Nowadays, with a follow-up period of three years, she is still under trientine and mesalazine therapy and asymptomatic, without any documented UC exacerbation while on $\mathrm{Cu}$ chelation therapy. During the followup period she had a pregnancy that progressed uneventfully.

\section{Discussion}

We report a new case of UC associated with WD, the fifth that we are aware since the first case ever reported in 2002 by Torisu Takahiro [12]. All the cases previously described, reported UC complicating previous WD established diagnosis $[13,14]$. Our case report describes the association, only, for the first time, in the opposite direction: a case of WD preceded of UC diagnosis.

The possible association between the two diseases was discussed by Torisu et al, considering that $\mathrm{Cu}$ acts as a scavenger of oxygen-free radicals during the inflammatory process. The $\mathrm{Cu}$ overload in the tissues induces excessive oxidative stress which affects the liver (contributing to inflammation followed by fibrosis and cirrhosis) and the gut (namely the colonic mucosa), where the reactive oxygen in- termediates (ROI) helps the promotion of chronic intestinal inflammation and immune activation [12].

Although human $\mathrm{Cu}$ metabolism is not completely understood, it is known that blood and tissue concentrations of $\mathrm{Cu}$ increase dramatically in WD, in inflammation and in other known conditions [15]. In patients with UC (either active or in remission) there is evidence of high serum levels of $\mathrm{Cu}$ and zinc, related to acute phase proteins as well as to hematological parameters of relapse [16]. As Torisu et al described, and as confirmed by other studies, proteins containing $\mathrm{Cu}$ and zinc used by the organism as scavengers of ROI, such as superoxide dismutase and metallothionein, are present in decreased levels in the colonic mucosa of patients with active UC and may have a role in the pathogenesis of the disease $[12,17]$.

So, a correlation may be established between high $\mathrm{Cu}$ levels in UC and in WD. UC relapses could also be a consequence of high levels of $\mathrm{Cu}$ induced by WD.

In our patient, abdominal pain, leukocytosis and elevated acute phase proteins may suggest a concomitant UC exacerbation during acute liver disease. It is known that high levels of alpha1-antitrypsin could be correlated with UC exacerbation, and $\mathrm{C}$ reactive protein and blood leukocytes are noninvasive markers for endoscopically active disease [18]. Nevertheless, at that time, no colonoscopy or colorectal mucosa biopsies were made to confirm such hypothesis.

Copper chelation in patients with $\mathrm{UC}$ and high $\mathrm{Cu}$ levels may be considered as a part of therapy, but further studies are needed to confirm their role in the course of UC. This implies that UC would appear as a consequence of a silent WD.

Even though WD and UC are both genetic diseases, different chromosomes are implied. In spite of that there are genetic mechanisms that control copper metabolism and homeostasis, related to copper absorption in many of the mammalian tissues, namely in the enterocyte, controlled by Ctr1 (a plasma membrane copper transport protein) [19]. It seems that copper transporter $\mathrm{Ctr} 1$ is downregulated when $\mathrm{Cu}$ is overloaded in the hepatocytes in WD [20]. If so, the downregulation of $\mathrm{Ctr} 1$ expression could lead to an augmentation of intestinal $\mathrm{Cu}$ content and inflammatory exacerbation, but a relationship between this transporter and inflammatory bowel disease has not yet been described.

Given the rarity of the reported association between these two diseases, we cannot refute that it could be merely a coincidence, in spite of the mechanisms explained before.

In conclusion, this is the fifth case report published worldwide of a patient presenting with both UC and WD, two rare entities. It seems that $\mathrm{Cu}$ plays a central role in both diseases, contributing to fibrosis and cirrhosis of the liver and probably to the immune activation in UC.

We hope that this report elicits further studies concerning the mechanisms associating UC and WD, and stimulates the report of new cases, to allow its real prevalence to be established. 


\section{Conflict of Interest}

The authors declare no conflict of interest.

\section{References}

1. La Fontaine S, Mercer JF. Trafficking of the copperATPases, ATP7A and ATP7B: role in copper homeostasis. Arch Biochem Biophys 2007;463(2):149-167.

2. de Bie P, van de Sluis B, Burstein E, van de Berghe PV, Muller P, Berger R, Gitlin JD, et al. Distinct Wilson's disease mutations in ATP7B are associated with enhanced binding to COMMD1 and reduced stability of ATP7B. Gastroenterology 2007;133(4):1316-1326.

3. Lech T, Hydzik P, Kosowski B. Significance of copper determination in late onset of Wilson's disease. Clin Toxicol (Phila) 2007;45(6):688-694.

4. Hassan A, Masood F. Wilson's disease: a review. J Pak Med Assoc 2004;54(9):479-484.

5. Mak CM, Lam CW. Diagnosis of Wilson's disease: a comprehensive review. Crit Rev Clin Lab Sci 2008;45(3):263-290.

6. Ferenci P. Regional distribution of mutations of the ATP7B gene in patients with Wilson disease: impact on genetic testing. Hum Genet 2006;120(2):151-159.

7. Podolsky DK. Inflammatory bowel disease. N Engl J Med 2002;347(6):417-429.

8. Marrero F, Qadeer MA, Lashner BA. Severe complications of inflammatory bowel disease. Med Clin North Am 2008;92(3):671-686, ix.

9. Terg R, Sambuelli A, Coronel E, Mazzuco J, Cartier M, Negreira S, Munoz A, et al. Prevalence of primary sclerosing cholangitis in patients with ulcerative colitis and the risk of developing malignancies. A large prospective study. Acta Gastroenterol Latinoam 2008;38(1):26-33.

10. Bergquist A, Montgomery SM, Bahmanyar S, Olsson R, Danielsson A, Lindgren S, Prytz H, et al. Increased risk of primary sclerosing cholangitis and ulcerative colitis in first-degree relatives of patients with primary sclerosing cholangitis. Clin Gastroenterol Hepatol 2008;6(8):939943.
11. Saich R, Chapman R. Primary sclerosing cholangitis, autoimmune hepatitis and overlap syndromes in inflammatory bowel disease. World $\mathrm{J}$ Gastroenterol 2008;14(3):331-337.

12. Torisu T, Esaki M, Matsumoto T, Nakamura S, Azuma $\mathrm{K}$, Okada M, Tsuji H, et al. A rare case of ulcerative colitis complicating Wilson's disease: possible association between the two diseases. J Clin Gastroenterol 2002;35(1):43-45.

13. Worns MA, Lohse AW, Neurath MF, Croxford A, Otto G, Kreft A, Galle PR, et al. Five cases of de novo inflammatory bowel disease after orthotopic liver transplantation. Am J Gastroenterol 2006;101(8):1931-1937.

14. Jang HJ, Jang JY, Kim KM. Appendiceal Orifice Inflammation in an 8-Year-Old Girl with Ulcerative Colitis Complicating Wilson's Disease. Gut Liver 2010;4(1):126-128.

15. Turnlund JR. Human whole-body copper metabolism. Am J Clin Nutr 1998;67(5 Suppl):960S-964S.

16. Dalekos GN, Ringstad J, Savaidis I, Seferiadis KI, Tsianos EV. Zinc, copper and immunological markers in the circulation of well nourished patients with ulcerative colitis. Eur J Gastroenterol Hepatol 1998;10(4):331337.

17. Mulder TP, Verspaget HW, Janssens AR, de Bruin PA, Pena AS, Lamers CB. Decrease in two intestinal copper/ zinc containing proteins with antioxidant function in inflammatory bowel disease. Gut 1991;32(10):1146-1150.

18. Schoepfer AM, Beglinger C, Straumann A, Trummler M, Renzulli P, Seibold F. Ulcerative colitis: Correlation of the Rachmilewitz endoscopic activity index with fecal calprotectin, clinical activity, C-reactive protein, and blood leukocytes. Inflamm Bowel Dis 2009;15(12):1851-1858.

19. Kuo YM, Gybina AA, Pyatskowit JW, Gitschier J, Prohaska JR. Copper transport protein (Ctr1) levels in mice are tissue specific and dependent on copper status. J Nutr 2006;136(1):21-26.

20. Ralle M, Huster D, Vogt S, Schirrmeister W, Burkhead JL, Capps TR, Gray L, et al. Wilson disease at a single cell level: intracellular copper trafficking activates compartment-specific responses in hepatocytes. J Biol Chem 2010;285(40):30875-30883. 